\title{
Uji Mutu Fisik Metoklopramid HCl Tablet Chewable dengan Variasi Jenis Pengisi sebagai Diluent menggunakan Metode Granulasi Basah
}

\author{
Umi Latifiana1, Deny Budi Legowo ${ }^{*}$, Erna Fitriany1, Andri Priyoherianto1, \\ Muhammad Novianto Ainul Huri ${ }^{1}$
}

${ }^{1}$ Akademi Farmasi Mitra Sehat Mandiri Sidoarjo

${ }^{*}$ E-mail:denilegowoo@gmail.com

Article Info:

Received: 24 April 2021

in revised form: 21 Mei 2021

Accepted: 29 Mei 2021

Available Online: 29 Mei 2021

Keywords:

Metoclopramide $\mathrm{HCl}$

Chewable tablets

Mannitol

Sucrose

Lactose

Corresponding Author:

Deny Budi Legowo

${ }^{1}$ Akademi Farmasi Mitra Sehat

Mandiri Sidoarjo

E-mail:

denilegowoo@gmail.com

\begin{abstract}
Background:

Metoclopramide $\mathrm{HCl}$ are used to reduce vomiting and nausea. Chewable tablet is the new product as the alternative ways to treatment children and adult patient who had difficulity problem of swallowing drugs. Objectives: This research aims to formulate the chewable metoclopramide $\mathrm{HCl}$ tablets using diluent variations to get a better physical quality test. Material and Methods:Chewable tablets of metoclopramide $\mathrm{HCl}$ are made using diluent variations, they are mannitol, sucrose, lactose. Formula I mannitol, formula II sucrose, and formula III lactose. Chewable tablet preparations are made by the wet granulation method. Data collection was performed on physical characteristics including organoleptic, weight uniformity, uniformity of size, tablet hardness, tablet fragility, disintegration time, metoclopramide $\mathrm{HCl}$ levels. Physical quality test results were statistically analyzed to determine the effect of variations in the diluent on the characteristics of chewable tablets. Results: The results of this research have an influence on the physical quality and uniformity of contents of various types of diluent variations between each formulation. In this research, fillers have an important role in the preparation of chewable metoclopramide tablets to determine the physical quality of the tablets and the uniformity of their contents. The variation of diluent that gives better results is mannitol. This is because formulas that use mannitol have uniformity in content that meets the requirements, faster disintegration time, and physical quality of tablets that still meet the requirements, when compared to the first and second formulations. Conclusions: The variation of diluent that gives better results is mannitol.
\end{abstract}


How to cite (APA $6^{\text {th }}$ Style):

Latifiana. U.,dkk. (2021). Mutu Fisik Metoklopramid HCl Tablet Chewable dengan Variasi Jenis Pengisi sebagai Diluent menggunakan Metode Granulasi Basah. Indonesian Journal of Pharmaceutical (e-Journal), 1(2), 67-75.

\section{ABSTRAK}

Metoklopramid $\mathrm{HCl}$ digunakan untuk meredakan mual dan muntah. Ketersediaan di pasaran dalam bentuk tablet, sirup dan injeksi. Pemakaian oral yang paling disukai pasien karena kemudahannya dalam penggunaan. Tablet Chewable yang merupakan produk baru sebagai alternative untuk pengobatan pasien anak-anak dan dewasa yang mengalami kesulitan dalam menelan obat. Penelitian ini bertujuan untuk memformulasi sediaan tablet chewable Metoklopramid $\mathrm{HCl}$ menggunakan variasi diluent untuk mendapatkan uji mutu fisik yang lebih baik. Sediaan tablet chewable metoklopramid $\mathrm{HCl}$ dibuat dengan menggunakan variasi diluent yaitu manitol, sukrosa, laktosa. Formula I mannitol, formula II sukrosa,dan formula III laktosa. Sediaan tablet chewable di buat dengan metode granulasi basah. Pengumpulan data dilakukan terhadap karakteristik fisik meliputi organoleptik, keseragaman bobot, keseragaman ukuran, kekerasan tablet, kerapuhan tablet, waktu hancur, kadar Metoklopramid $\mathrm{HCl}$. Hasil uji mutu fisik dianalisis secara statistik untuk mengetahui pengaruh variasi diluent terhadap karakteristik tablet chewable. Hasil penelitihan ini terdapat pengaruh terhadap mutu fisik dan keseragaman kandungan dari perbedaan variasi jenis diluent antara masing-masing formulasi.Dalam penelitian ini bahan pengisi memiliki peran penting dalam pembuatan sediaan tablet chewable metoklopramid untuk menentukan mutu fisik tablet dan keseragaman kandungan. Variasi diluent yang memberikan hasil yang lebih baik adalah manitol. Hal ini dikarenakan formula yang menggunakan manitol memiliki keseragaman kandungan yang memenuhi persyaratan, waktu hancur yang lebih cepat, dan mutu fisik tablet yang masih memenuhi persyaratan, bila dibandingkan dengan formulasi kesatu dan formulasi kedua.

Kata Kunci: metoclopramide $\mathrm{HCl}$, tablet chewable, jenis variasi pengisi (manitol, sukrosa, laktosa).

\section{Pendahuluan}

Metoklopramid merupakan suatu derivat antagonis reseptor dopamin dengan sifat prokinetik dan antiemetik[1]. Metoklopramid menjadi salah satu obat yang paling banyak diberikan untuk gangguan motilitas gastrointestinal karena sifat prokinetiknya.Saat ini Metoklopramid yang telah beredar di pasar berada dalam bentuk sediaan tablet, sirup dan injeksi. Rute pemakaian secara oral merupakan rute yang paling disukai karena kemudahan dalam penggunaan, menghindari rasa sakit, dan meningkatkan kepatuhan pasien. Kesulitan dalam menelan dan keefefan dalam pemakaian terjadi adanya penurunan penyerapan merupakan permasalahan yang sering terjadi, dalam mengkonsumsi sediaan tablet maupun larutan ${ }^{[2]}$.

Tablet chewable yang merupakan tablet kunyah yang memberikan rasa manis atau tidak pahit (menutupi rasa pahit). Keuntungan yang dimiliki tablet kunyah jika dibandingkan sediaan padat oral lainnya meliputi ketersediaan hayati yang lebih baik, tablet kunyah memiliki bioavaibilitas yang lebih baik dengan adanya proses disintegrasi yang meningkatkan disolusi, kenyamanan pasien dengan meniadakan kebutuhan air minum untuk menelan, dapat digunakan sebagai pengganti bentuk sediaan cair jika diperlukan kerja obat (onset) yang cepat, meningkatkan penerimaan pasien (terutama anak - anak) karena cita rasa yang menyenangkan dan memiliki keunikan produk dari sudut pandang pemasaran ${ }^{[3]}$.

Proses pembuatan tablet secara granulasi basah, kering, atau kempa langsung dapat diterapkan pada tablet kunyah seperti pada tipe tablet lainnya. Metode pembuatan 
tablet kunyah terdiri dari granulasi basah, granulasi kering dan cetak langsung, granulasi itu sendiri digunakan untuk meningkatkan laju alir dan kompresibilitas serbuk dan mencegah adanya segresi. Diantara ketiga metode, metode granulasi basah merupakan metode yang paling sering dipilih karena dapat memperbaiki sifat alir masa cetak, dan dapat menghasilkan tablet yang tidak rapuh. Metode ini cocok digunakan untuk Active Pharceutical Ingredients (API's) yang bersifat termolabil[4,5].

Formulasi untuk zat aktif yang kecil dan kelembapan tinggi sehingga dapat mengakibatkan kemungkinan terjadinya zat aktif tidak homogen akibat zat aktif yang sangat kecil yang tidak terkendali selama proses pencampuran pada metode kempa langsung. Selain itu dapat menghindari zat aktif dari tumbukan. Salah satu bahan tambahan yang harus diperhatikan untuk mencapai tablet yang bermutu adalah konsistensi pengisi. Bahan pengisi mempengaruhi sifat fisik dari tablet yaitu pada kompabilitas dan kompresi, dan juga berfungsi memperbesar volume massa agar mudah di cetak atau dibuat, oleh sebab itu perlu dilakukannya penelitian bahan pengisi apa yang dapat menghasilkan sifat fisik tablet yang baik ${ }^{[6,7]}$.

Umumnya dalam pembuatan tablet kunyah menggunakan diluent seperti manitol, sorbitol, atau sukrosa sebagai bahan pengisi $[7,8]$. Bahan pengisi yang digunakan dalam tablet kunyah ini adalah manitol, sukrosa, dan laktosa ). Manitol merupakan bahan pengisi terpilih pada kebanyakan formulasi tablet kunyah, baik yang dibuat dengan cetak langsung maupun granulasi basah. manitol lebih banyak dipilih karena higroskopisitas yang rendah, kompresibilitas yang baik dan rasanya manis ${ }^{[9]}$. Keuntungan manitol adalah mempunyai rasa yang manis, memberi sensasi yang dingin pada mulut, bersifat tidak higroskopis, mudah kering pada saat proses granulasi. Sukrosa merupakan serbuk bersifat kohesif solid, mempunyai kestabilan yang baik pada temperatur kamar dan kelembapan yang cukup, sukrosa bekerja sebagai pengikat kering ( $2-20 \% \mathrm{w} / \mathrm{w}$ ) atau sebagai bulking agent dan pemanis pada tablet kunyah, sedangkan laktosa adalah bahan pengisi yang banyak digunakan karena harganya murah dan merupakan bahan pengisi yang inert.

Berdasarkan uraian diatas akan dilakukan penelitian lebih lanjut terkait perbedaan bahan pengisi (diluent) (manitol, sukrosa dan laktosa) dalam pembuatan sediaan tablet kunyah metoklopramid HCI dengan metode granulasi basah secara spektrofotometri UV-Vis hingga didapat mutu fisik tablet chewable yang baik.

\section{Metode}

Alat yang digunakan dalam penelitian ini adalah spektrofotometer UV-Vis, oven, mikropipet, alat pencetak tablet, hardness tester, friability tester, disintegration tester, timbangan digital, alat gelas .Bahan yang digunakan dalam penelitian ini antara lain: metoklopramid $\mathrm{HCl}$, manitol, sukrosa, laktosa, polivinil pirolydone, aspartam, magnesium stearate, asam sitrat, aquadest, kalium dihydrogen phosphate (KH2PO4), natrium hidroksida $(\mathrm{NaOH})$.

2.1 Pembuatan sediaan tablet chewable metoclopramide $\mathrm{HCl}$

Formulasi tablet kunyah metoklopramide $\mathrm{HCl}$ dibuat dengan metode granulasi basah masing-masing dibuat dengan menggunakan bahan pengikat manitol, sukrosa dan laktosa[10].

Perhitungan kandungan

Bobot per tablet $=800 \mathrm{mg}$

Kandungan Metoclopramide $\mathrm{HCl}$ per tablet $=5 \mathrm{mg}$

1 batch $=300$ tablet 
2.2 Prosedur pembuatan pembuatan tablet Chewable metoclopramide $\mathrm{HCl}$

Tabel 1. Komposisi formula

\begin{tabular}{ccccc}
\hline Bahan & Fungsi & F1 & F2 & F3 \\
\hline Metoklopramid HCl & Zat Aktif & $5 \mathrm{mg}$ & $5 \mathrm{mg}$ & $5 \mathrm{mg}$ \\
& Pengisi & Manitol & Sukrosa & Laktosa \\
Polivinil pilydone & Pengikat & $2 \%$ & $2 \%$ & $2 \%$ \\
Aspartam & Pemanis & $1 \%$ & $1 \%$ & $1 \%$ \\
Asam Sitrat & Flavoring & $0,5 \%$ & $0,5 \%$ & $0,5 \%$ \\
Magnesium Stearat & Pelicin & $2 \%$ & $2 \%$ & $2 \%$ \\
Red No 40 & Pewarna & $\mathrm{qs}$ & & \\
Yellow No 05 & Pewarna & & $\mathrm{qs}$ & \\
Orange & Pewarna & & & $\mathrm{qs}$ \\
\hline
\end{tabular}

Uji evaluasi mutu granul dilakukan dengan cara berikut: Uji sifat alir dilakukan dengan menimbang $100 \mathrm{~g}$ granul, lalu di alirkan melalui corong dengan jarak corong dengan dasar adalah $10 \mathrm{~cm}$. Batas alir maksimum adalah 10 detik [11].Pengujian dilakukan dengan menuangkan melalui corong dengan ukuran tertentu, diletakan pada ketinggian tertentu dan diletakan diatas bidang datar. Luas dan tinggi gundukan kemudian diukur[11]. Kompresibilitas dapat dilihat dari harga indeks Carr yang sangat bergantung pada kerapatan nyata maupun kerapatan mampat dari granul yaitu dengan cara kerapatan mampat dikurangi kerapatan nyata, lalu dibagi dengan kerapatan mampat[11]. Uji organoleptis dilakukan dengan melakukan pengamatan pada fisik tablet yang diamati meliputi tidak ada capping, cracking, picking dan karakteristik lain yang menandakan adanya kerusakan tablet[11]. Uji keseragaman bobot tablet dilakukan dengan menimbang 20 tablet dan dihitung rata-rata tiap tabletnya, tidak boleh ada lebih dari dua tablet yang bobotnya lebih dari angka yang tercantum dalam kolom $\mathrm{A}$, dan hasil timbang tablet tidak boleh menyimpang dari tabel B. Berikut adalah tabel persyaratan keseragaman bobot tablet [11]. Uji kerapuhan tablet dilakukan dengan menggunakan alat friability tester dengan cara menimbang 20 tablet, lalu dicatat bobot sebelum di masukkan alat. Setelah itu di masukan ke dalam alat dan mesin jalankan dengan kecepatan 25 rpm selama 4 menit kemudian ditimbang bobot tablet setelah di lakukan pengujian. Syarat kerapuhan tablet yang dikehendaki adalah sebesar $1 \%$ atau kurang untuk tablet konvensional, sedangkan untuk tablet kunyah (karena kekerasan yang lebih rendah), nilai friabilitas sampai $4 \%$ dapat diterima[11]. Uji waktu hancur dilakukan menggunakan alat desintegran dengan cara memasukkan 6 tablet kedalam keranjang yang tersedia. Lalu keranjang di naik turunkan ke dalam cairan pelarut hingga hancur. Tablet dinyatakan memiliki waktu hancur yang baik apabila tablet tersebut hancur dalam waktu kurang dari 15 menit dan tidak lebih dari 30 menit untuk tablet salut gula dan salut selaput[11].

3. Hasil dan Pembahasan

Uji spesifisitas yakni untuk penentuan panjang gelombang suatu zat. Secara teoritik Metoklopramid $\mathrm{HCl}$ memiliki panjang gelombang maksimum 309nm[11]. Penentuan 
kurva baku metoklopramid $\mathrm{HCl}$ dalam penelitian ini menggunakan spektrofotometri UV-Vis dengan menggunakan panjang gelombang 307nm. Menurut Farmakope Indonesia penentuan panjang gelombang maksimal metoklopramide $\mathrm{HCl}$ adalah 309nm. Penentuan linieritas dilakukan dengan pembuatan baku kerja dengan beberapa konsentrasi metoklopramid $\mathrm{HCl}$ dan diamati absorbansinya menggunakan spektrofotometri UV-Vis. Hasil linieritas metoklopramid $\mathrm{HCl}$ dapat dilihat pada tabel 2.

Tabel 2. Linearitas larutan baku kerja Metoklopramid $\mathrm{HCl}$

\begin{tabular}{ccc}
\hline No. Standart & Konsentrasi $(\mathbf{p p m})$ & Absorbansi $(A B S)$ \\
\hline $\mathbf{1}$ & 6 & 0.2121 \\
$\mathbf{2}$ & 8 & 0.2823 \\
$\mathbf{3}$ & 10 & 0.3453 \\
$\mathbf{4}$ & 12 & 0.4089 \\
$\mathbf{5}$ & 14 & 0.4827 \\
$\mathbf{6}$ & 16 & 0.5468 \\
$\mathbf{7}$ & 18 & 0.6185 \\
$\mathbf{8}$ & 20 & 0.6872 \\
$\mathbf{9}$ & 22 & 0.7536 \\
\hline
\end{tabular}

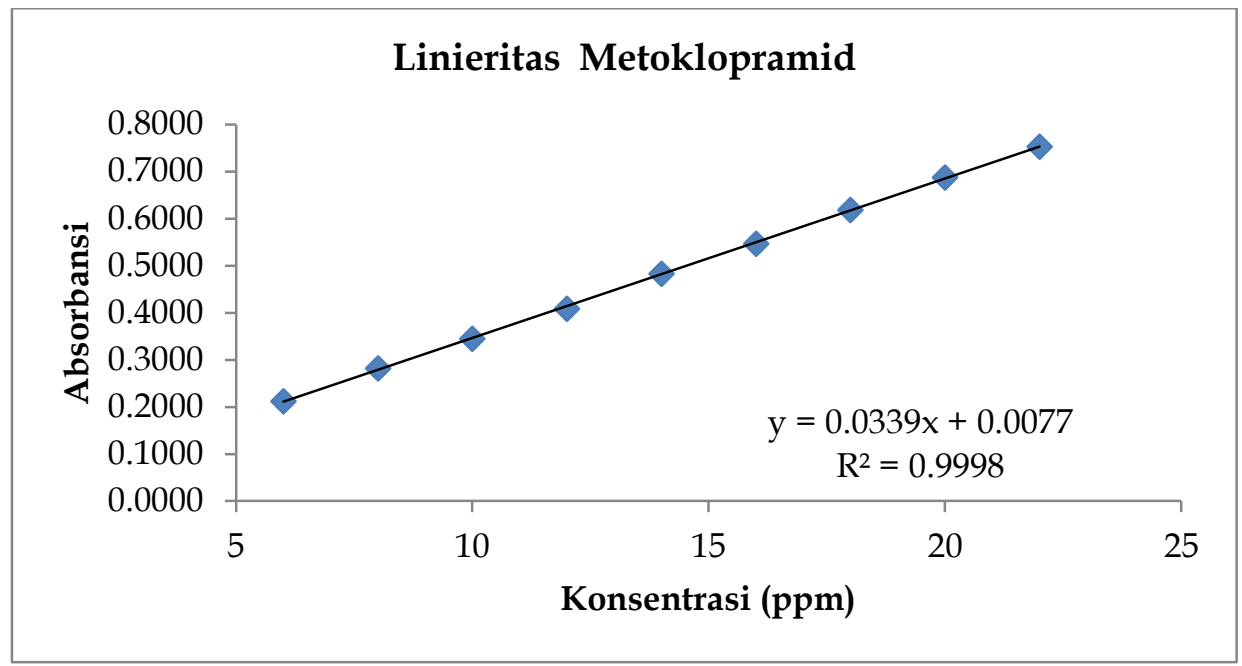

Gambar 1. Linearitas metoklopramid $\mathrm{HCl}$

Dalam penentuan linieritas metoklopramid $\mathrm{HCl}$ dengan konsentrasi ppm. 6,0 ppm. 8,0 ppm. 10,0 ppm. 12,0 ppm. 14,0 ppm. 16,0 ppm. 18,0 ppm. 20,0 ppm. 22,0 ppm didapatkan persamaan regresi $Y=0,0339 x+0,0077$ dan nilai koefisien $R^{2}=0,9998$. Penentuan linieritas metoklopramid $\mathrm{HCl}$ pada penelitian ini dapat disimpulkan bahwa kurva kalibrasi dari deretan konsentrasi dan absorbansi pada metoklopramid $\mathrm{HCl}$ tersebut linier.

\subsection{Penentuan Uji LOD dan LOQ}

Penentuan LOD dan LOQ dilakukan dengan mengamati absorbansi larutan baku kerja dengan konsentrasi menggunakan spektrofotometri. Penentuan LOD dapat dihitung dengan $\mathrm{LOD}=3 \mathrm{X}$ sd/Slope sedangkan LOQ dapat dihitung dengan rumus LOQ $=10 X S D /$ Slope . 
Tabel 3. LOD dan LOQ

\begin{tabular}{ccccc}
\hline Jenis Zat Uji & Panjang Gelombang $(\mathbf{n m})$ & $\begin{array}{c}\text { Rentang } \\
\text { Konsentrasi }\end{array}$ & $\begin{array}{c}\text { LOD } \\
\text { (ppm) }\end{array}$ & $\begin{array}{c}\text { LOQ } \\
\text { (ppm) }\end{array}$ \\
\hline Metoklopramid HCl & 307,7599 & $6,0-22,0$ & 0,2581 & 0,8636
\end{tabular}

\subsection{Uji susut pengeringan}

Setelah proses pencampuran bahan-bahan ini terbentuklah massa granul yang sudah melewati tahap pengayakan yang menggunakan ayakan mesh no.14. Massa granul yang sudah terbentuk dilakukan pengovenan sampai masa granul mendapatkan masa air kurang dari $<10 \%$ di dapatkan hasil dari pengujian susut pengeringan dapat dilihat pada tabel 4.

Tabel 4. Uji susut pengeringan.

\section{Tabel Uji Susut Pengeringan}

\begin{tabular}{ccccc}
\hline Sampel Uji & Bobot Awal & Bobot Akhir & Selisih & $\%$ \\
Formulasi I & 176.244 & 164.84 & 0.0647 & 6.5 \\
Formulasi II & 185.144 & 169.282 & 0.0857 & 8.6 \\
Formulasi III & 175 & 166.729 & 0.0473 & 4.7
\end{tabular}

Berdasarkan data, maka F2 di dapatkan masa air 4,8 namun persyaratan tersebut masih di bawah standart penentuan jadi granul tersebut di oven kembali untuk penambahan waktu pemanasan, setelah di lakukan pengovenan didapatkan 8,6\% namun formulasi tersebut sangat mudah lembab ini di pengaruhi oleh kandungan sukrosa yang terbagi bersifat higroskopis dan menyerap hingga $1 \%[7,11]$. bahan pengisi yang mudah menyerap oksigen, dilanjutkan uji evaluasi granul untuk menyatakan bahwa granul yang sudah terbentuk memenuhi persyaratan untuk selanjutnya dilakukan proses cetak tablett[12]. Uji evaluasi granul meliputi uji waktu alir, uji sudut diam dan kompresibilitas.

\subsection{Uji waktu alir}

Metode corong merupakan metode pengukuran yang sangat sederhana dan langsung dapat diketahui kecepatan atau waktu yang dibutuhkan sejumlah serbuk untuk mengalirkan. Pada umumnya serbuk dikatakan mempunyai sifat alir yang baik jika 100gram serbuk yang diuji mempunyai waktu alir $\leq 10$ detik [13].

Tabel 5. Uji waktu alir

\section{Tabel Uji Waktu Alir}

\begin{tabular}{|c|c|c|c|c|c|c|c|c|}
\hline \multicolumn{2}{|c|}{ Uji Sifat Alir } & \multicolumn{3}{|c|}{ Sebelum + lubrikan } & \multicolumn{3}{|c|}{ Sesudah + lubrikan } & \multirow[t]{2}{*}{ SD } \\
\hline & & W & $\mathrm{T}$ & $\mathrm{w} / \mathrm{t}$ & W & $\mathrm{T}$ & $w / t$ & \\
\hline \multirow[t]{3}{*}{ Formulasi } & $\mathrm{I}$ & 100 & 13,13 & 7,6 & 100 & 9,16 & 10,9 & 0,096 \\
\hline & II & 100 & 15,46 & 6,5 & 100 & 10,21 & 9,8 & 0,131 \\
\hline & III & 100 & 8,50 & 11,8 & 100 & 8,12 & 12,3 & 0,129 \\
\hline
\end{tabular}


Penelitian ini didapatkan hasil dimana F1, F2, F3 terjadi perbedaan yang mana pada F2 tidak memenuhi persyaratan Farmakope Indonesia yakni membutuhkan waktu alir 10,2 detik ini bisa disebabkan oleh beberapa faktor salah satunya bentuk granul yang tidak homogen dan banyaknya serbuk halus dan bahan pengisi bersifat higroskopis, dalam penambahan asam sitrat $0,5 \%$ tidak mempengaruhi mutu fisik granul disebabkan dalam table I: Uses of citric acid monohydrate konsentrasi 0,2 - 2,0\% untuk menambahkan perasa dalam tablet[14].Berdasarkan uji one way Anova, didapatkan nilai signifikan $0,000(p<0,05)$ yang artinya terdapat perbedaan yang signifikan sifat alir granul antar formula tablet chewable metoklopramid $\mathrm{HCl}$.

3.4 Uji sudut diam

Uji sudut diam pada granul yang memenuhi persyaratan yaitu dari $20^{\circ}<\theta<40^{\circ}$. Hasil penelitian ini pada formulasi pertama diperoleh rata-rata sudut diam $31,4^{\circ}$, formulasi kedua diperoleh rata-rata sudut diam $31,7^{\circ}$, dan formulasi ketiga diperoleh rata-rata $32,9^{\circ}$ dalam hal ini di dapatkan hasil yang kurang baik disebabkan oleh beberapa faktor salah satunya banyaknya partikel halus dalam granul dan faktor suhu pada lingkungan penyimpanan yang menyebabkan granul lembab sehingga laju alir pada mesin cetak tablet tidak terlalu cepat meluncur ataupun terlalu lamban. Berdasarkan uji one way Anova, didapatkan nilai signifikan 0,007 ( $<<0,05)$ yang artinya terdapat perbedaan yang signifikan pada uji kompresibilitas antar formula tablet kunyah metoklopramid $\mathrm{HCl}$.

Tabel 6. Uji sudut diam

\begin{tabular}{lcccc}
\hline Uji Sudut Diam & F1 & F2 & F3 & Standart \\
\hline Rata- Rata & 31,4 & 31,7 & 32,9 & $20-40$ \\
SD & 0,36 & 0,40 & 0,40 &
\end{tabular}

3.4 Uji kompresibilitas

Hasil penelitian uji kompresibiltas didapatkan F1 (13\%), F2 (17\%), F3 (12\%).

Persentase kompresibilitas ketiga formula tersebut memenuhi persyaratan kompresibilitas granul yang baik. Hasil ini juga menunjukkan bahwa ketiga formulasi mempunyai sifat alir yang baik karena kompresibilitas tidak lebih dari 20\%[15]. Dapat dilihat pada tabel 10 Analisis data uji kompresibilitas pada halaman 47, Berdasarkan uji one way Anova didapatkan nilai signifikan $0,000(\mathrm{p}<0,05)$ yang artinya terdapat perbedaan yang signifikan pada massa granul. Maka hubungan antara kompresibilitas dan waktu alir dalam cetak tablet adalah makin kecil nilai kompresibiltas akan mempunyai sifat alir yang lebih cepat.

Tabel 7. Uji kompresibilitas

\begin{tabular}{lllllll}
\hline Formula & W (gram) & V (ml) & $\mathbf{B}(\mathrm{g} / \mathbf{m l})$ & $\begin{array}{l}\text { Kompresibilitas } \\
(\%)\end{array}$ & $\begin{array}{l}\text { Rata- } \\
\text { rata }\end{array}$ & SD \\
\hline F1 & 54,844 & 100 & 0,548 & 13 & 13 & 0,4 \\
& 54,531 & 100 & 0,545 & 13 & & \\
& 54,624 & 100 & 0,546 & 13 & &
\end{tabular}




\begin{tabular}{lllllll}
\hline F2 & 59,282 & 100 & 0,593 & 17 & 16 & 0,8 \\
& 60,538 & 100 & 0,605 & 15 & & \\
& 60,811 & 100 & 0,608 & 16 & 13 & 0,5 \\
F3 & 52,728 & 100 & 0,527 & 12 & & \\
& 52,298 & 100 & 0,523 & 13 & & \\
& 52,143 & 100 & 0,521 & 13 &
\end{tabular}

\subsection{Uji kekerasan tablet}

Uji kekerasan tablet didefinisikan sebagai uji kekuatan tablet yang mencerminkan kekuatan tablet secara keseluruhan, yang diukur dengan memberi tekanan terhadap diameter tablet kekuatan tablet diberi skala dalam kilogram ${ }^{[16]}$. Kekerasan tablet yang baik adalah 3-5 kP[13]. Faktor-faktor yang mempengaruhi kekerasan tablet adalah tekanan kompresi dan sifat bahan yang dikempa. Kekerasan ini dipakai, sebagai ukuran dari tekanan pengempaan. Semakin besar tekanan yang diberikan saat cetak tablet akan meningkatkan kekerasan tablet[13]. Hasil uji kekerasan pada F1 2,2 kp, F2 2,7 kp dan F3 2,8 kp dimana ketiga formulasi tersebut tidak memenuhi persyaratan kekerasan tablet kunyah. Disebabkan karena banyaknya partikel halus pada granul sehingga mempengaruhi waktu percetakan tablet saat pengisi granul ke day tidak konstan. Hasil uji Kruskal-Wallis didapatkan nilai signifikan 0,000 $(\mathrm{p}<0,05)$ yang artinya terdapat perbedaan yang signifikan pada uji kekerasan tablet antar formula tablet kunyah metoklopramid $\mathrm{HCl}$.

Tabel 8. Uji kekerasan tablet

\section{Tabel Uji Kekerasan}

Standart

$\begin{array}{ccccc}\text { Formulasi } & \text { I } & \text { II } & \text { III } & \\ \text { Rata-rata } & 2,2 & 2,7 & 2,8 & 3 \\ \text { SD }<\mathbf{2 \%} & 0,4 & 0,5 & 0,4 & \end{array}$

\subsection{Uji waktu hancur}

Uji waktu hancur (disintegransi) tablet dapat dinyatakan hancur jika terlarut dalam suatu medium penguji atau hancur menjadi banyak partikel. Langkah penting pertama sebelum melarut adalah pecahnya tablet menjadi partikel kecil atau granul yang disebut disintegrasi[10]. uji waktu hancur dilakukan untuk mengetahui waktu yang dibutuhkan oleh tablet untuk dapat hancur dalam suatu cairan, yang dikondisikan sebagai cairan gastrointestinal.

Tabel 9. Uji waktu hancur

\section{Tabel Waktu Hancur}

\begin{tabular}{ccc} 
Formulasi & Rata-rata (menit $)$ & SD \\
I & 10.11 & 0.04 \\
II & 15.30 & 0.05 \\
III & 4.07 & 0.04 \\
\hline
\end{tabular}


3.5 Uji mutu granul keseluruhan

\begin{tabular}{|c|c|c|c|c|c|c|}
\hline \multirow{2}{*}{$\begin{array}{l}\text { parameter- } \\
\text { parameter }\end{array}$} & \multicolumn{2}{|c|}{ Manitol } & \multicolumn{2}{|c|}{ Sukrosa } & \multicolumn{2}{|c|}{ Laktosa } \\
\hline & memenuhi & $\begin{array}{c}\text { tidak } \\
\text { memenuhi }\end{array}$ & memenuhi & $\begin{array}{c}\text { tidak } \\
\text { memenuhi }\end{array}$ & memenuhi & $\begin{array}{c}\text { tidak } \\
\text { memenuhi }\end{array}$ \\
\hline sifat alir & $\sqrt{ }$ & & & $\sqrt{ }$ & $\sqrt{ }$ & \\
\hline sudut diam & $\sqrt{ }$ & & $\sqrt{ }$ & & $\sqrt{ }$ & \\
\hline Kompresibilitas & $\sqrt{ }$ & & $\sqrt{ }$ & & $\sqrt{ }$ & \\
\hline $\begin{array}{l}\text { keseragaman } \\
\text { bobot }\end{array}$ & $\sqrt{ }$ & & $\sqrt{ }$ & & $\sqrt{ }$ & \\
\hline $\begin{array}{l}\text { keseragaman } \\
\text { ukuran }\end{array}$ & & $\sqrt{ }$ & & $\sqrt{ }$ & & $\sqrt{ }$ \\
\hline Kekerasan & & $\sqrt{ }$ & & $\sqrt{ }$ & & $\sqrt{ }$ \\
\hline Kerapuhan & $\sqrt{ }$ & & $\sqrt{ }$ & & $\sqrt{ }$ & \\
\hline waktu hancur & $\sqrt{ }$ & & & $\sqrt{ }$ & $\sqrt{ }$ & \\
\hline $\begin{array}{l}\text { keseragaman } \\
\text { kandungan }\end{array}$ & $\sqrt{ }$ & & $\sqrt{ }$ & & $\sqrt{ }$ & \\
\hline$\%$ & & & & & & 7 \\
\hline
\end{tabular}

Dari tabel hasil uji mutu granul dan mutu fisik tablet kunyah metoklopramide $\mathrm{HCl}$ diatas dapat disimpulkan bahwa tablet dengan bahan pengisi manitol menghasilkan tablet kunyah metoklopramide $\mathrm{HCl}$ yang kekerasan relative rendah, kerapuhan kecil dan waktu hancur yang memasuki persyaratan itu bisa disebabkan karena banyaknya partikel halus pada granul sehingga mempengaruhi waktu pencetakan tablet saat pengisian granul ke day tidak konstan. Tablet dengan bahan pengisi sukrosa menghasilkan tablet kunyah metoklopramide $\mathrm{HCl}$ yang kekerasannya besar, kerapuhan relative kecil dan waktu hancurnya yang lama itu bisa disebabkan karena bahan tambahan bersifat higroskopis sehingga lama untuk larut. Tablet dengan pengisi laktosa menghasilkan tablet kunyah metoklopramide $\mathrm{HCl}$ yang kekerasannya kecil, kerapuhannya kecil dan waktu hancurnya cepat. Manitol dan Laktosa memberikan hasil uji mutu fisik yang hampir sama, akan tetapi bahan pengisi yang lebih baik digunakan adalah manitol dikarenakan laktosa bahan tambahan kurang efektif dalam pembuatan tablet kunyah disebabkan kurang manisnya bahan tambahan tersebut karena faktor paling penting dalam pembutan tablet kunyah adalah rasa yang manis.

\section{Kesimpulan}

Berdasarkan penelitian yang dilakukan maka dapat disimpulkan bahwa bahan pengisi memiliki peran penting daalama pembuatan sediaan tablet kunyah metoklopramid untuk menentukan mutu fisik tablet dan keseragaman kandungan. Variasi diluent yang memberikan hasil paling baik adalah manitol.

\section{Referensi}

[1] Sweetman, S.C., 2016, Martindale The Complete Drug Reference, Thirty Sixth Edition, Pharmaceutical Press, New York 
[2] Neha SL, Neelam S, Yasir M. Sstained release solid dispersion of metoclopramide hydrochloride: formulation, evaluation, and pharmacokinetic studies. J Appl Pharma Sci 2015;5:55-65.

[3] Sateesh KV, Prabhakar RV. Colon specific controlled release matrix tablets of flurbiprofen: development and characterization. Asian J Pharm Clini Res 2012;5:92-6.

[4] Ranjith PS, Ratna KT, Satyajit P. Formualtion development and evaluation of sustained release ibuprofen tablets with acrylic polymers and HPMC. Int J Pharma Pharma Sci 2016;8:131-5

[5] Jaya $S$ and Amala V. Formulation and invitro evaluation of oral disintegrating tablets of amlodipine besylate. Int J Appli Pharmaceutics 2019; 11:49-54

[6] Wadher KJ, Ghodasare $\mathrm{Ch}$ and Umekar MJ. Formulation and evaluation of controlled release matrix tablets using eudragit RSPO and gum copal. Int J Pharm and chemical Res 2017; 3: 1-7.

[7] Tjay, Tan Hoan dan Kirana Rahardja. 2007. Obat-Obat Penting Khasiat, Penggunaan dan Efek-Efek Sampingnya, Edisi Keenam. Jakarta: PT. Elex Media Komputindo

[8] Chang R, Robinson JR. Sustained release from tablets and particles through coating In: H.A. Libreman, L. Lachman and J.B. Schwart (Eds), Pharmaceutical dosage forms: Tablets, 2 nd Edn. Vol.3, Marcel Dekker, 1990.199-302.

[9] Faas, R., Thompsons, J. R., Pienieszek, H. J. 2009. Pharmacokinetic comparison of orally- disintegrating metoclopramide with conventional metoclopramide tablet formulation in healthy volunteers, Aliment Pharmacol Theraphy, 30: hal 301-306.

[10] Ansel, H.C. 2017. Ansel's Pharmaceutical Dosage Forms And Drug Delivery Systems. Ninth Edition. Philadelphia.

[11] Hadisoewignyo L. and Fudholi A. 2013. Sediaan Solida. Pustaka Pelajar: Yogyakarta.

[12] Solanki, H.K., Basuri T., Thakkar, J.H., and Patel, C.A., 2018. Recent Advences in Granulation Technology. International Journal of Pharmaceutical Sciences Review and Research, Vol. 5, Issue 3.

[13] Syamsuni, 2006, Farmasetika Dasar Dan Hitungan Farmasi, Penerbit Buku Kedokteran EGC, Jakarta.

[14] Kumar, D, D S Goswami, P Tomar, S Kaur. 2014. Formulation And Characterization Of Chewable Tablets Of Paracetamol And Metoclopramide Hydrochloride. Barnala: S. D. College of Pharmacy.

[15] Rowe, R.C. et Al. 2008.Handbook Of Pharmaceutical Excipients, 6thEd, The Pharmaceutical Press, London.

[16] Sheth, B.B., Bandelin F.J., Shangraw R.F. 2016. Compressed Tablet, in Lachman L., Lieberman H.A., Kanig J.L. (editor). Pharmaceutical Dosage Forms, Tablets, Volume I. New York: Marcel Dekker Inc. 